\title{
Mentoring for career development
}

Ann Rolfe

Mentoring Works, Umina Beach, Australia

Many mentoring programs are aimed at assisting participants with career management but just how can a mentor help? This article gives some activities to assist with career development conversations.

Career management involves assessing the current situation and making informed decisions about the future. It requires reflection (thoughtful assessment of yourself and your situation) and action (deliberate movement toward selected goals). You can do this alone; however, a trusted confidante who can skilfully listen and question, may elicit insights that may otherwise remain unavailable. A mentor's own experience may add perspective, can offer an opinion, and may provide extra information and access to resources. Finally, a mentor means not having to "go it alone" on the career journey.

\section{Assessing the current reality}

Take a good look at yourself and where you are in life and your career.

A detailed conversation with a mentor will help you to get clear about what you like and dislike about:

(1) Your job content: Are you doing what you enjoy and what you are good at in the work tasks, activities, role, and responsibilities?

(2) The work environment: Do the people, physical surroundings, and organisational culture bring out your best? Is the field you work in something you value?

(3) Work/life: How does work impact on how you want to live life? Does it match your personal values and goals?

A personal stock-take is in order. A mentor will ask:

(1) What knowledge, skills, experience, and other strengths and career assets have you?

(2) What interests and motivates you?

(3) In terms of your personality, are you a people person who wants to help or serve, a fix-it type, in to technology, machines, and tools? Are you in love with ideas or happier working with solid data? Is your nature inquisitive, driven by the quest for knowledge or is your preference artistic expression?

(4) What values and beliefs guide your priorities right now?

(5) What personal considerations, such as relationships, finances, family, health, education, and other commitments, need to be taken into account in your decision making?

Having assessed the current reality, it is time to imagine future possibilities. The value of the mentor earlier was their ability to stimulate introspection and examination of the present; now the mentor encourages

Korean J Med Educ 2017 Jun; 29(2): 117-119.

https://doi.org/10.3946/kjme.2017.59

eISSN: 2005-7288

(C) The Korean Society of Medical Education. All rights reserved.

This is an open-access article distributed under the terms of the Creative

Commons Attribution Non-Commercial License (http://creativecommons.org/ licenses/by-nc/3.0/), which permits unrestricted non-commercial use, distribution, and reproduction in any medium, provided the original work is properly cited. 
looking outward and contemplating future prospects. Creativity, optimism, and good information are vital at this stage so that you can entertain many possibilities before you set more specific goals.

\section{Identify the ideal occupation}

It is not uncommon to target a particular job as a career goal. However, that can be limiting and distract you from other possibilities that may be equally, or more, satisfying. It also sets up a win-lose situation, OK if you win the job you want but what if you miss out? Many people tie their sense of self-worth to career achievement. Therefore self-esteem, motivation, and performance can take a nosedive as a result of perceived "failure." Finally, fixing on a particular job is problematic because the rapid rate of change in the world of work means radical shifts occur almost overnight. Old jobs disappear and new occupations emerge. There are those that say job titles are themselves obsolete. While there will always be plenty of work to do, it will not come in neat little packages that can be easily labelled with a job title.

As an alternative to a goal such as "I want to be a ..." or "I want job xyz" try defining the ideal occupation using the exercise below and make it your aim.

I'd like to work where..

(1) I am able to use my preferred knowledge, skills, and experience of $\cdots$

(2) In a field that matches my interests in $\cdots$

(3) So that I can contribute to the goals of my employer by $\cdots$

And,

(1) I am working toward my personal/career goals of $\cdots$

(2) My work satisfies my needs/wants to $\cdots$

(3) My employment does not compromise my values of $\cdots$

(4) I work with people who $\cdots$

(5) I work in an environment where $\cdots$
(6) The intrinsic rewards of my work are:

(7) The extrinsic rewards of my work are:

Share your responses with your mentor. Compare the ideal that you have described with current reality. Discuss what is working well for you right now and how you might close the gaps between what you have and what you would like.

\section{Making informed decisions}

Now you are ready to explore and evaluate the many possibilities you generated earlier. You will need to research them, separating fact from speculation and opinion. Gather data from a variety of reliable sources. Narrow down the list of possibilities to a few options that appear to align with your ideal occupation and allow you to set a general direction for your actions. The mentor acts as a facilitator of the inward looking self-assessment and the outward looking exploration of options before assisting you to develop plans and identify the resources you need to implement them. This is a practical phase where the mentor is a collaborator and creativity, combined with pragmatism is used to generate and evaluate various strategies.

\section{The mentoring conversation}

The mentor facilitates this kind of career planning by leading a conversation based on four questions (Fig. 1) [1]:

(1) Where are you now?

(2) Where do you want to be?

(3) How might you get there? And, as the mentoree starts to act on their plan,

(4) How are you doing?

The aim of the mentoring conversation is to enable the mentoree to reflect on their experience and take stock, make informed decisions about their options, set goals, plan, and then implement appropriate actions. 
Fig. 1. Mentoring Conversation
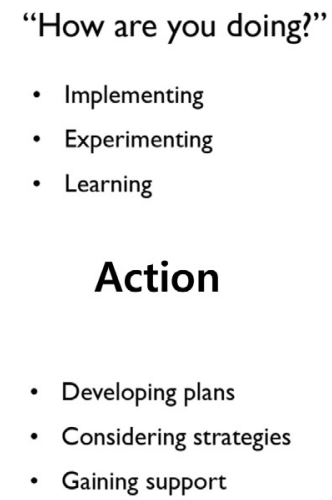

"How might you get there?"

\section{Experience}

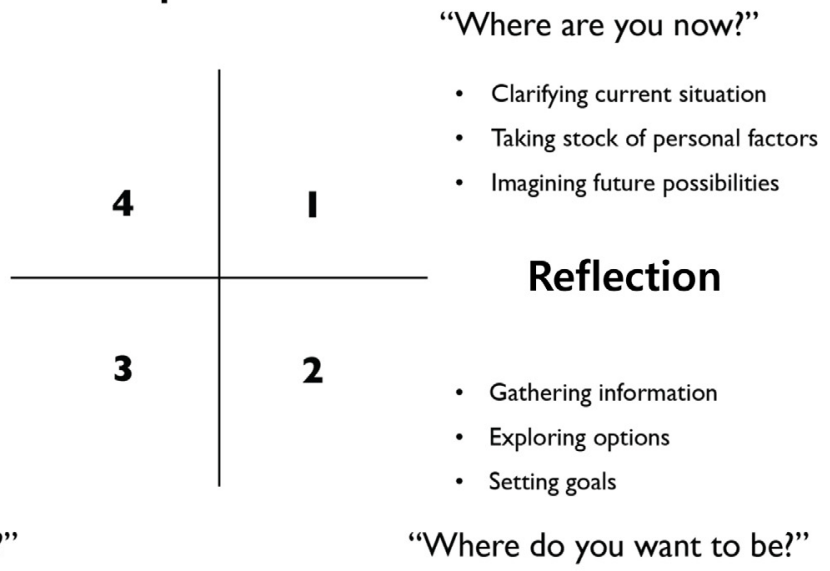

Informed decisions

From Rolfe A. Mentoring guide. Kincumber South, Australia: Mentoring Works; 2007 [1].

The mentor has at least three alternatives for generating information as a basis for decision-making:

(1) Draw ideas from the mentoree and help them use their existing knowledge;

(2) Assist the mentoree to find and access other reliable sources; or,

(3) Offer information and advice based on personal knowledge and experience.

Because mentoring is an adult-to-adult process, the mentor is a guide and an aid to the mentoree's decisionmaking. The mentor does not dictate to, or direct, the mentoree. The mentor can offer suggestions, relate their own experience, or offer ideas. The mentor can also use skilful questioning to enhance the analysis of information and identify faulty logic.

The mentoring conversation is a practical demonstration of a problem solving and decision-making process that can be applied in any situation. So mentoring assists with immediate needs and equips the mentoree to deal with future issues. As the saying goes "Give a person a fish and you feed them for a day; teach a person how to fish and they can feed themselves for a lifetime." This is particularly important because career planning is not a one-off event. Career management is an ongoing cycle of reflection and action and life-long learning and growth. In the context of careers, change is the only constant. We are living longer, with better health and activity levels and often have what's been labelled "encore careers" in our senior years. The need for meaningful work (paid or unpaid) is intrinsic. So, career planning and development is something you may expect to do again and again. The assistance of a mentor is a bonus. Mentoring others stimulates thinking about one's own potential, possibilities, and opportunities.

\section{Reference}

1. Rolfe A. Mentoring guide. Kincumber South, Australia: Mentoring Works; 2007. 